\title{
ANALISIS MINAT SISWA TERHADAP MATA PELAJARAN FISIKA DI SMA N 1 BATANGHARI
}

Tiara sandari

Program Studi Pendidikan Fisika, Universitas Jambi, Jambi, Indonesia

Coreresponding author email: tiarasandari0@gmail.com

\section{Info Artikel}

Diterima:

2 November 2020

Disetujui:

3 Desember 2020

Dipublikasikan:

15 Desember 2020

\begin{abstract}
Abstrak:
Minat belajar memiliki pengaruh terhadap hasil belajar. Apabila seseorang yang tidak memiliki minat pada pelajaran tertentu maka sulit untuk mencapai hasil pembelajaran yang optimal. Sebaliknya apabila seseorang yang memiliki minat pada mata pelajaran tertentu maka akan mencapai hasil pembelajaran yang optimal. Minat akan terbentuk jika ada usaha dari dalam dirinya dan juga ada dorongan dari luar baik itu dari guru, keluarga, dan lingkungan sekitar untuk mengukai, mempelajari dan mengerjakan soal-soal fisika yang diberikan oleh guru. Tujuan penelitian ini adalah untuk mengetahui minat siswa terhadap mata pelajaran fisika dari hasil deskripsi sikap siswa SMA N 1 Batanghari. Jenis penelitian ini yaitu kuantitatif menggunakan prosedur penelitian survei dengan instrumen yang digunakan adalah angket. Subjek penelitian ini adalah 50 siswa SMA N 1 Batanghari. Hasil penelitian menunjukkan bahwa minat belajar siswa SMA N 1 Batanghari pada kelas X MIPA 1, X MIPA 2, X MIPA 3 pada plajaran fisika sudah baik walaupun ada beberapa siswa yang minat belajarnya masih kurang. Agar minat belajar siswa pada pelajaran fisika lebih baik dan lebih meningkat, guru harus menggunakan pendekatan, dan model yang lebih inovatif serta menggunakan media yang lebih menarik agar siswa tertarik untuk mengikuti pembelajaran..
\end{abstract}

Kata Kunci : Fisika, minat belajar, siswa

\begin{abstract}
:
Interesting in learning has influence on learning outcomes. If someone does not have an interest in a particular subject, it is difficult to achieve optimal learning outcomes. Conversely, if someone who has an interest in certain subjects will achieve optimal learning results. Interesting will be formed if there is an effort from within him and there is also encouragement from the outside both from the teacher, family, and the surrounding environment to like, study and work on physics problems given by the teacher. The purpose of this study was to determine students' interest in physics from the descriptions of the attitudes of SMA N 1 Batanghari students. This type of research is quantitative using survey research procedures with the instrument used is a questionnaire. The subjects of this study were 53 students of SMA N 1 Batanghari. The result of data analysis and discussion, it can be concluded that the learning interest of SMA NI BATANGHARI students in physics lessons is good even though there are some students who are still less interested in learning.
\end{abstract}

Keywords:Physics, interesting in learning, students 


\section{Pendahuluan}

Pada saat ini potensi suatu bangsa atau Negara tidak lagi di nilai dari melimpahnya kekayaan alam tapi dinilai dari potensi sumber daya manusia yang terbentuk melalui dunia pendidikan.Pendidikan merupakan investasi sumber daya manusia (SDM) jangka panjang yang mempunyai nilai strategis bagi kelangsungan kehidupan manusia didunia. Pendidikan pada dasarnya adalah usaha sadar untuk menumbuh kembangkan potensi sumber daya manusia peserta didik dengan cara mendorong dan memfasilitasi kegiatan belajar mereka(Pratiwi, 2017). Menurut Asrial (2019) Pendidikan adalah upaya menciptakan sumber daya manusia yang berkualitas, sehingga penting untuk meningkatkan pendidikan di Indonesia.Untuk meningkatkan kualitas pendidikan di Indonesia, harus didukung juga oleh peningkatan kualitas tenaga kependidikannya.

Kegiatan belajar dan mengajar diarahkan untuk pembentukan mental, penciptaan lingkungan belajar yang dapat mempengaruhi pengembangan kognitif siswa dan membantunya agar lebih sadar terhadap proses berfikirnya, misalnya dalam hal kemampuan dasar siswa, pengetahuan, sikap dan motivasinya. Berhasil atau tidaknya pencapaian pembelajaran tidak lepas dari guru dalam menerapkan model dan metode yang dapat mendorong siswa untuk belajar.Menurut Chotimah (2018) Pembelajaran adalah usaha sadar dari seorang guru dalam rangka mencapai tujuan yang diharapkan untuk membelajarkan siswanya dan mengarahkan interaksi siswa dengan sumber belajar lainnya. Menurut Astuti (2015) Minat merupakan faktor penentu behasil tidaknya pendidikan. Dampak dari adanya suatu minat belajar bisa menumbuhkan cara baru dalam belajar peserta didik. Belajar dikatakan berhasil jika bisa menumbuhkan sikap, tingkah laku, dan cara berfikir dalam memecahkan permasalahan- permasalahan yang dihadapi.

Khodijah dkk (2016), menjelaskan bahwa partisipasi siswa sangat penting dalam pelaksanaan proses pembelajaran di kelas. Dengan meningkatnya partisipasi siswa maka prestasi belajar siswa juga akan semakin meningkat. Menurut Basuki dkk (2019), mengatakan bahwa dalam suatu pembelajaran diperlukan suatu penilaian untuk mengetahui perkembangan, kemajuan, dan hasil belajar siswa selama pembelajaran program pendidikan itu dilaksanakan. Hasil belajar merupakan realisasi tercapainya tujuan pendidikan, sehingga hasil belajar yang diukur sangat tergantung dengan tujuan pendidikannya (Kurnia, dkk., 2016). Sedangkan menurut Arrasyid dkk (2017), Hasil belajar merupakan patokan nsyang digunakan untuk menentukan tingkat keberhasilan siswa dalam mengetahui dan memahami suatu mata pelajaran yang dapat berupa pengetahuan nilai dari keterampilan setelah siswa mengalami proses belajar.

Menurut Pasaribu dkk (2017), Hasil belajar merupakan suatu prestasi yang dicapai seseorang dalam mengikuti proses pembelajaran yang dapat diukur dari hasil latihan atau ulangan yang diambil dari materi yang telah disampaikan. Menurut Sipahutar dkk (2018), perubahan hasil belajar dapat terlihat pada tingkah laku dan antusiasme peserta didik dalam mengikuti pembelajaran.

Menurut Primadona (2018) Fisika merupakan pengetahuan yang disusun berdasarkan fakta, fenomena-fenomena alam, hasil pemikiran, dan hasil eksperimen. Pemahaman terhadap konsep Fisika dapat dijadikan bekal untuk melanjutkan pendidikan pada jenjang yang lebih tinggi serta mengembang sikap kritis dalam mengembangkan ilmu pengetahuan dan teknologi. Pada kenyataannya pelajaran fisika kurang diminati siswa pada umumnya, karena dianggap sulit, sehingga proses pembelajaran fisika tidak sesuai seperti yang diharapkan. Masalah siswa dalam belajar di kelas salah satunya adalah kurang memahami konsep materi pelajaran. Kesulitan itu kemudian yang menyebabkan kurangnya minat siswa terhadap mata pelajaran fisika. Hal ini yang menyebabkan aktivitas siswa dalam mengikuti pembelajaran fisika di kelas menjadi rendah. Menurut (Supardi et al., 2012) Rendahnya hasil belajar Fisika siswa disebabkan oleh banyak hal antara lain: kurikulum yang padat, materi pada buku pelajaran yang dirasakan terlalu sulit untuk di ikuti, media belajar yang kurang efektif, laboratorium yang tidak memadai, kurang tepatnya penggunaan media pembelajaran yang dipilih oleh guru, kurang optimal dan kurangnya keselarasan siswa itu sendiri, atau sifat konvesional, dimana siswa tidak banyak terlibat dalam proses pembelajaran dan keaktifan kelas sebagian besar didominasi oleh guru.

Menurut Oktaviana dkk (2016) kurangnya minat siswa dalam belajar fisika dan kurangnya keaktifan siswa dalam proses pembelajaran. Sebagian siswa menganggap bahwa belajar fisika itu susah karena hanya mempelajari rumus-rumus dan mengaplikasikan dalam perhitungan, sehingga kemampuan logika-matematika siswa yang lemah akan mengalami kesulitan dalam belajar fisika, serta Analisis Minat Siswa... (Tiara Sandari) hal:118-123 
dalam tuntutan kurikulum 2013 diperlukan suatu kegiatan pembelajaran yang mendorong partisipasi aktif siswa. Tujuan penelitian ini adalah untuk mengetahui minat siswa terhadap mata pelajaran fisika dari hasil deskripsi sikap siswa SMA N 1 Batanghari.

\section{Metode Penelitian}

Jenis penelitian yang digunakan adalah penelitian kuantitatif dengan pendekatan deskriptif dimana data yang diambil berdasarkan fakta - fakta yang diperoleh. Menurut Hamdi dan Bahruddin (2014), penelitian deskriptif (descriptive research) adalah suatu metode penelitian yang ditujukan untuk menggambarkan fenomena- fenomena yang ada tanpa adanya rekayasa dan manipulasi keadaan..Tujuan dari penelitian ini yaitu untuk mengetahui bagaimana minat belajar peserta didik terhadap mata pelajaran fisika sehingga dapat mempengaruhi hasil belajar peserta didik di SMA Negeri 1 Batanghari.Penelitian ini dilakukan mulai dari tanggal 15 Oktober 2020 - 25 Oktober 2020 di SMAN 1 Batanghari, dengan sampel seluruh siswa kelas XI, yaitu XI MIPA 1, dan XI MIPA 3. Dimana jumlah semua responden adalah 50.

Metode yang digunakan dalam penelitian ini yaitu Deskriptif Statistik, yaitu metode dengan instrumennya berupa angket dan tes yang dibagikan kepada siswa (sampel). Penelitian juga menggunakan metode kuantitatif deskriptif, dengan tujuan agar dapat menggambarkan karakteristik subjek yang diteliti.Langkah-langkah penelitian ini yaitu: 1) mengurus surat izin penelitian kepada pihak yang bersangkutan, 2) menentukan subjek penelitian, 3) melakukan pengambilan data penelitian menggunakan instrument tes yang dibagikan kepada peserta didik, 4) data yang diperoleh diolah dan dianalisis menggunakan software pengolahan data SPSS.

Teknik pengumpulan data yang digunakan yaitu teknik angket dan tes. Teknik angket digunakan untuk mengumpulkan data minat belajar peserta didik. Angket yang digunakan disusun menurut skala likert. Instrument penelitian yang digunakan meliputi angket untuk minat belajar peserta didik yang terdiri dari 4 kriteria jawaban yaitu SS: Sangat Setuju, S : Setuju, TS : Tidak Setuju dan STS : Sangat Tidak Setuju. Data yang diperoleh di analisis dengan menggunakan teknik statistic deskriptif . Dalam penelitian ini nilai yang terdapat pada kriteria jawaban bergantung pada aspek pernyataan positif maupun negatif. Pernyataan dimulai dari angka 4, 3, 2, dan 1.

\section{Hasil Dan Pembahasan}

Penyebaran angket melalui google formulir kepada siswa, data hasil angket dihitung dengan menggunakan skala likert. Dalam instrumen berupa angket terdapat 25 butir pernyataan dan 5 indikator minat belajar dari brown (Hendriana, 2017 ).

\section{Tabel 1. Hasil Minar siswa}

\begin{tabular}{clc}
\hline No & \multicolumn{1}{c}{ Indikator } & Persentase \\
\hline 1 & Perasaan senang belajar fisika & $83,54 \%$ \\
2 & Ketertarikan siswa belajar fisika & $60,14 \%$ \\
3 & Keterlibatan siswa belajar fisika & $95,35 \%$ \\
4 & Rajin dalam belajar dan mengerjakan Tugas fisika & $63,67 \%$ \\
5 & Tekun dan disiplin dalam belajar fisika & $66,03 \%$ \\
\hline
\end{tabular}

Dari tabel diatas yaitu perasaan senang belajar fisika ,ketertarikan siswa belajar fisika keterlibatan siswa belajar fisika, rajin dalam belajar dan mengerjakan tugas fisika ,tekun dan disiplin dalam belajar fisika. Indikator yang memiliki persentase tertinggi adalah keterlibatan siswa belajar fisika ,dan dari 4 pernyataan yaitu saya sering melamun dalam kelas ketika belajar fisika, bila ada materi pelajaran sulit dipahami , saya meminta guru mengulanginya, dalam belajar fisika saya berusaha memahami rumus-rumus penting ,pelajaran fisika mempunyai banyak teori dan rumus kebanyakan siswa menjawab setuju pada pernyataan posistif dan tidak setuju pada pernyataan negatif.Sedangkan persentase yang paling rendah adalah indikator ketertarikan siswa dalam belajar fisika yaitu $60,14 \%$ dari 5 pernyataan . kebanyakan siswa menjawa setuju pada pernyataan negatif dan tidak setuju pada pernyataan positif. Sehingga terlihat ketertarikan siswa dalam belajar fisika. 
Tabel 2. Kriteria Interpretasi Skor Berdasarkan Interval

\begin{tabular}{ll}
\hline Presentasi & Kriteria \\
\hline $0 \%-19,99 \%$ & Sangat kurang baik \\
$20 \%-39.99 \%$ & Kurang baik \\
$40 \%-59,99 \%$ & Cukup \\
$60 \%-79,99 \%$ & Baik \\
$80 \%-100 \%$ & Sangat baik \\
\hline
\end{tabular}

Berdasarkan tabel 1 dan 2 terdapat 2 indikator yang memenuhi kriteria sangat baik dan 3 indikator memenuhi kriteria baik.

Menurut Astalini (2018) Minat belajar fisika siswa yang rendah menyebabkan siswa malas mengerjakan tugas, kurang suka membaca buku atau hal-hal yang berkenaan dengan fisika, dan merasa senang bila tidak belajar fisika karena guru tidak hadir. Hal ini akan mengganggu proses belajar siswa dan membuat tujuan pembelajaran tidak tercapai. Menurut Aminoto (2019) Hal ini disebabkan kurangnya minat dan motivasi untuk mempelajari fisika dengan senang hati, sehinga banyak siswa merasa kurang tertarik untuk mempelajari fisika. Hal ini ternyata terjadi sampai pada tingkat yang lebih tinggi yakni Universitas. Joneska dkk (2016), Salah satu solusi untuk meningkatkan keaktifan, minat serta perhatian siswa dalam proses pembelajaran adalah dengan mengkondisikan siswa untuk dapat belajar secara aktif dengan saling berbagi informasi dengan temannya.

Menurut Jufrida (2019) Faktor internal merupakan faktor-faktor yang berasal dari diri peserta didik yang mempengaruhi hasil belajar. Salah satu faktor fisiologis yang meliputi motivasi, belajar, minat belajar, dan kebiasaan belajar. Dengan minat belajar yang tinggi siswa dapat memperoleh pengetahuan dan wawasan serta hasil belajar yang baik. Dalam pembelajaran guru harus melihat kondisi siswa, karena kondisi siswa sangat penting untuk diperhatikan. Kondisi siswa yang sangat penting adalah bagaimana minatnya dalam mata pelajaran. Siswa yang berminat akan lebih perhatian dan akan lebih ingin tahu terhadap mata pelajaran yang dipelajarinya. Minat yang kuat akan menimbulkan usaha yang gigih dan tidak putus asa dalam menghadapi tantangan (Charli et al., 2019). Menurut Putri dkk (2018), Lingkungan belajar tidaklah lepas dari keberadaan siswa dalam belajar. Kebiasaan belajar siswa dipengaruhi oleh kebiasaan siswa dalam belajar di sekolah, di rumah maupun di masyarakat. Menurut Alwan dkk (2017), Lingkungan keluarga dan masyarakat diupayakan agar dapat menciptakan suasana yang kondusif bagi keberlangsungan kegiatan belajar.

\section{Simpulan}

Berdasarkan hasil analisis data dan pembahasan diatas maka dapat disimpulkan bahwa minat belajar siswa SMA N 1 Batanghari pada kelas X MIPA 1 , X MIPA 2, X MIPA 3 pada plajaran fisika sudah baik walaupun ada beberapa siswa yang minat belajarnya masih kurang. Agar minat belajar siswa pada pelajaran fisika lebih baik dan lebih meningkat, guru harus menggunakan pendekatan, dan model yang lebih inovatif serta menggunakan media yang lebih menarik agar siswa tertarik untuk mengikuti pembelajaran.

\section{Referensi}

Alwan., Hendri, M., Darmaji. (2017). Faktor-Faktor Yang Mendorong Siswa MIA SMAN Mengikuti Bimbingan Belajar Luar Sekolah Di Kecamatan Telanaipura kota Jambi. Jurnal Edufisika, 2(1), 25-37

Aminoto, T., Dani, R., Yuversa, E. (2019). Pengembangan Termometer Gas Sebagai Alat Peraga Pembelajaran Pokok Bahasan Skala Suhu Mutlak. Jurnal Edu Fisika, 4(2), 4855.

Arrasyid, H., Jufrida., Darmaji. (2017). Aktivitas Dan Hasil Belajar Siswa Dengan Menggunakan Model Pembelajaran Problem Based Learning Berbantuan Lembar Kerja Siswa Pada Materi Kalor Dan Perpindahannya Kelas X SMA PGRI 2 Jambi. Jurnal Edufisika, 2(2), 68-80. 
Astalini., Kurniawan, Dwi. A., Sumaryanti. (2018). Sikap Siswa Terhadap Pelajaran Fisika Di SMAN Kabupaten Batanghari. Jurnal Ilmu Pendidikan Fisika, 3(2), 59-64.

Astuti, Siwi. P. (2015). Pengaruh Kemampuan Awal dan Minat Belajar Terhadap Prestasi Belajar Fisika. Jurnal Formatif, 5(1), 65-75

Basuki, F, R., Jufrida., Kurniawan, W., Devi, I P., \& Fitaloka, O. (2019). Tes Keterampilan Proses Sains: Multiple Choice Format. Jurnal Pendidikan Sains (JPS), 7(2), 101-111

Charli, L., Ariani, T., \& Asmara, L. (2019). Hubungan Minat Belajar terhadap Prestasi Belajar Fisika. Science and Physics Education Journal (SPEJ), 2(2), 52-60.

Chotimah, C., Hendri, M., Rasmi, D P. (2018). Penerapan LKS Berbasis Inkuiri Terbimbing pada Materi Listrik terhadap Hasil Belajar Siswa Kelas IX SMPN 22 Kota Jambi. Jurnal Penelitian Pembelajaran Fisika, 9(1), 36-39.

Hamdi, A. S, \& Bahruddin, E. (2014). Metode Penelitian Kuantitatif Aplikasi dalam Pendidikan. Yogyakarta: Deepublish

Hendriana, H., Rohaeti, E., \& Sumarmo, U. (2017). Hard Skills dan Soft Skills . Bandung: Refika Aditama

Joneska, A., Astalini., Susanti, N. (2016). Perbandingan Hasil Belajar Fisika Menggunakan Strategi Pembelajaran Crossword Puzzle Dan Index Card Match Pada Materi Cahaya Kelas VIII SMP Negeri 3 Batanghari. Jurnal EduFisika, 1(1), 28-31

Jufrida., Basuki, F, R., Pangestu, M, D., Prasetya, N A D. (2019). Analisis Faktor Yang Mempengaruhi Hasil Belajar IPA Dan Literasi Sains Di SMP Negeri 1 Muaro Jambi. Jurnal EduFisika, 4(2), 31- 38.

Khodijah, Dwinda, N., Hendri, M., Darmaji. (2016). Upaya Meningkatkan Partisipasi Dan Hasil BelajarDengan Menggunakan Model Pembelajaran Kooperatif Tipe Think Pair Share Di Kelas XI MIA7 SMAN 1 Muaro Jambi. Jurnal EduFisika, 1(2), 46-54.

Kurnia, N., Hendri, M., Pathoni, H. (2016). Hubungan Persepsi Dengan Hasil Belajar Fisika Siswa Kelas X MIA Di SMAN Negeri 4 Kota Jambi Dan SMA Negeri 11 Kota Jambi. Jurnal EduFisika, 1(2), 55-63.

Kurniawan, Dwi.A., Astalini., Kurniawan, Nugroho. (2019). Sikap Siswa Terhadap Pelajaran IPA Di SMP Kabupaten Muaro Jambi Provinsi Jambi. Journal Of Teaching And Learning. 4(3), 111127

Oktaviana, D., Jufrida., Darmaji. (2016). Penerapan RPP Berbasis Multiple Intelligences Untuk Meningkatkan Aktivitas Dan Hasil Belajar Fisika Siswa Pada Materi Kalor Dan Perpindahan Kalor Kelas X MIA 4 SMA Negeri 3 Kota Jambi. Jurnal EduFisika, 1(1), 7-12.

Pasaribu, Dewi, S., Hendri, M., Susanti, N. (2017). Upaya Meningkatkan Minat Dan Hasil Belajar Fisika Siswa Dengan Menggunakan Model Pembelajaran Talking Stick Pada Materi Listrik Dinamis Di Kelas X SMAN 10 Muaro Jambi. Jurnal EduFisika, 2(1), 61-69. 
Pratiwi, N. K. (2017). Pengaruh Tingkat Pendidikan, Perhatian Orang Tua, Dan Minat Belajar Siswa Terhadap Prestasi Belajar Bahasa Indonesia Siswa Smk Kesehatan Di Kota Tangerang. Pujangga, 1(2), 31.

Primadona, H., Nehru., Kurniawan, W. (2018). Perbandingan Motivasi Belajar Siswa Dengan Menggunakan Media Lectora InspireDan Powerpoint Pada Materi Momentum Dan Impuls kelas X SMAN 3 Muaro Jambi. Jurnal EduFisika, 3(1), 43-54.

Putri, A, R., Maison., Darmaji. (2018). Kerjasama Dan Kekompakan Siswa Dalam Pembelajaran Fisika Di Kelas XII MIPA SMAN 3 Kota Jambi. Jurnal EduFisika, 3(2), 32-40.

Simatupang, R, Y., Jufrida., Aminoto, T. (2017). Upaya Meningkatkan Aktivitas Dan Hasil Belajar Fisika Siswa Dengan Menggunakan Model Pembelajaran Inkuiri Tipe Guided Inquiry Di Kelas XI MIA 2 SMA Negeri 11 Kota Jambi. Artikel Ilmiah. Jambi: Universitas Jambi

Sipahutar, M., Hendri, M., Dani, R. (2018). Model Discovery Learning Berbantuan Media Adobe Flash CS 6 Pada Materi Hukum Newton. Jurnal EduFisika, 3(2), 59-65.

Supardi, Leonard, L., Suhendri, H., \& Rismurdiyati. (2012). Pengembangan Media Pembelajaran dan Minat Belajar Terhadap Hasil Belajar Fisika. Jurnal Formatif, 2(1), 71-81. 